\title{
APRENDENDO COM OS POVOS DA AMAZÔNIA*
}

\author{
Cláudio Perani, SJ \\ Informações do artigo \\ Recebido em 05/05/2018 \\ Aceito em 05/06/2018. \\ doi> 10.25247/2447-861X.2018.n244.p208-218
}

\begin{abstract}
Resumo
Inspirado pelos resultados da Campanha da Fraternidade de 2007, cujo tema foi "Vida e missão neste chão", Cláudio Perani nos convida neste texto a uma instigante reflexão a partir da ótica das diversas lutas e clamores dos povos da Amazônia. Elegendo como guia o projeto de uma sociedade mais solidária e de um novo modelo de cidadania, integrado pela visão deflorestania e pelo sonho da Terra sem Males, o Autor questiona a noção de uma região atrasada, incapaz de administrar suas grandes riquezas e sempre dependente do resto mundo, e nos deixa com a seguinte provocação: não seria exatamente o contrário?

Palavras-Chave: Lutas Populares. Povos Amazônicos. Florestania.
\end{abstract}

\section{Introdução}

Este breve texto é um convite à reflexão. De maneira especial sobre as diversas lutas e clamores dos povos da Amazônia. Nele, retomamos os resultados da Campanha da Fraternidade de 2007, "Vida e missão neste chão". Ao menos a parte mais visível recolhida nos grupos de reflexão, nas celebrações comunitárias, nas rodas de conversa com os diversos grupos nas comunidades que acompanhamos. A outra parte são algumas anotações que realizamos durante os encontros de formação que assessoramos no decorrer do ano, especialmente com alguns grupos da Vida Religiosa. Por fim, há também reflexões que realizamos na Comissão Episcopal para a Amazônia, da qual participamos de alguns encontros em preparação para elaboração do Texto Base da Campanha da Fraternidade 2007.

Iniciamos a reflexão com algumas frases da poesia "quando a verdade for flama", da coletânea "Faz escuro, mas eu canto", do poeta amazonense Thiago de Mello que diz o seguinte:

\footnotetext{
* Este texto foi elaborado para aula inaugural da IV turma do Curso de Formação para Ação Social - FAS - do Serviço de Ação, Reflexão e Educação Social - SARES, realizada em Manaus - AM, em 19 de fevereiro de 2008.
} 
Quando a verdade for flama

As colunas da injustiça, sei que só vão desabar quando o meu povo, sabendo que existe, souber achar dentro da vida o caminho que leva à libertação. Vai tardar, mas saberá que esse caminho começa na dor que acende uma estrela no centro da servidão. De quem já sabe, o dever (luz repartida) é dizer. Quando a verdade for flama nos olhos da multidão, o que em nós hoje é palavra no povo vai ser ação.

\section{A força do povo}

Retomando a poesia por partes, propomos algumas reflexões pontuais que podem ajudar no aprofundamento dos desafios dessa nossa realidade tão sofrida e, ao mesmo tempo, carregada de lições de libertação.

a) "As colunas da injustiça - sei que só vão desabar quando o meu povo, sabendo que existe, souber achar dentro da vida o caminho - que leva à libertação. Vai tardar, mas saberá - que esse caminho começa na dor que acende uma estrela - no centro da servidão". Nestas palavras do poeta, em síntese está toda a Campanha da Fraternidade de 2007, "vida e missão neste chão". As "colunas da injustiça" representam a triste situação da Amazônia desde a invasão dos portugueses. Terra injustiçada porque não reconhecida em sua identidade e valor. Explorada em favor de interesses alheios.

b) "Meu povo": a Amazônia é uma terra habitada por um povo querido, que vive e sobrevive.

c) "Achar dentro da vida o caminho que leva à libertação": é esse povo, injustiçado, que no cotidiano de sua vida e de sua luta encontra o caminho da libertação. De fora, somente por alguém que souber reconhecer isso e se colocar a serviço de um projeto local.

d) "Na dor que acende uma estrela no centro da servidão": exatamente porque injustiçado o povo amazônida torna-se semente de libertação. Vários autores da 
teologia da libertação nos lembram essa realidade evangélica: no sofrimento, na cruz aparece o caminho da libertação, da ressurreição.

As palavras do poeta são muito atuais. Representam bem a caminhada do povo nessa imensa Amazônia e nos faz refletir profundamente sobre o papel da Igreja nessa região. São palavras que nos calam e nos convidam a uma profunda conversão. Conversão aqui, significa reconhecer o valor do povo. Um povo de muitos rostos e de muitos clamores. A conversão nos conduz a respeitar sua caminhada, seu tempo histórico e seu protagonismo.

Um povo de muitos rostos e de muitos clamores. A conversão nos conduz a respeitar sua caminhada, seu tempo histórico e seu protagonismo.

\section{A Campanha da Fraternidade de 2007}

A CF 2007 foi pensada para despertar a sociedade brasileira e os povos do mundo para conhecerem os valores e a criatividade dos povos da Amazônia, frente às agressões do atual modelo econômico e cultural, favorecendo a conversão à solidariedade, a um novo estilo de vida e de desenvolvimento humano.

Na conjuntura mundial atual, é algo de providencial, é um grito profético de alerta para o mundo inteiro, para o Brasil e para o próprio povo da Amazônia. A partir desta terra vem a denúncia, lúcida e violenta, deste modelo econômico neoliberal. Não somente, pois, também aparecem os caminhos, ainda tímidos, para uma nova sociedade mais solidária, para um novo modelo de cidadania, aqui integrado pela visão de florestania e pelo sonho da Terra sem Males, sonhado pela maioria dos povos indígenas e ribeirinhos da Amazônia. Para eles, a Amazônia é uma casa acolhedora de todos os povos das cidades e das florestas.

Não se trata, então, de ajudar a Amazônia para ela respeitar mais a floresta ou colaborar com a Igreja para crescer em sua organização. Trata-se de perceber a necessidade de uma profunda conversão da humanidade inteira e dos cristãos, em particular, questionados e iluminados pelo povo da Amazônia. A CF 2007 deve levar a uma tomada de consciência universal das grandes injustiças contra as populações da terra, não somente no sentido econômico, roubando a riqueza aqui existente, mas sobretudo pela visão falsa, pueril e discriminatória que existe em relação à Amazônia e seu povo, no Brasil e no mundo inteiro. Mesmo entre intelectuais e lideranças eclesiais. Mesmo para muitos bispos ainda permanece 
a visão muitas vezes internalizada na população local. Aquela visão de que a Amazônia precisa do resto mundo. Será que não seria exatamente o contrário? Imaginem quanta coisa bonita as outras regiões poderiam aprender com os povos da Amazônia!

\section{Na Amazônia existe um povo}

Desde o início da colonização os portugueses apareceram como uma civilização superior. Ignoraram totalmente a história milenares dos povos indígenas. Os estudiosos dizem que existiam na Amazônia brasileira de 5 a 20 milhões de indígenas. Não só, mas, consideravam os habitantes locais primitivos, selvagens, chegando a colocar em dúvida a existência da alma. Não deixavam, porém, de utilizar os indígenas para um trabalho escravo em suas fazendas de cacau e de gado. Coisas do passado?

A exploração econômica e política continua hoje, evidentemente, com novas formas e sutilezas consideradas por nós mais "civilizadas". O texto da CF é muito claro sobre isso. Lembra o desmatamento para o agronegócio, a mineração, a biopirataria. Hoje estão roubando até a água! Os projetos energéticos e viários das grandes rodovias e hidrovias para favorecer interesses externos. E podemos acrescentar o trabalho escravo, o narcotráfico, a militarização, a violência sempre maior, as cidades inumanas.

Só para lembrar um dado da perversão do modelo capitalista aqui implantado: a produção pecuária gera somente um emprego utilizando $30 \mathrm{~km}^{2}$, enquanto a agricultura familiar pode sustentar 100 pessoas em $2,5 \mathrm{~km}^{2}$.

O que mais nos interessa nessas breves linhas é considerar a visão folclórica e ideológica que ainda hoje permanece sobre a Amazônia veiculada na televisão em muitas partes do mundo e, infelizmente, na cabeça de muitos leigos, missionários, missionarias padres e bispos que aqui chegam. Não querem saber que aqui existe um povo! Sim. Aqui existe um povo! A Amazônia não é somente um ambiente físico, mas também um ambiente humano, com uma história social, política e econômica, com uma cultura própria, ou melhor, com várias culturas bem diversificadas entre si. Os índios não são personagens exóticos a serem contemplados por turistas, mas povos com grandes tradições, sabedoria e formas de vida criativas.

Quando o povo é lembrado, claro, não é mais chamado de "selvagem", mas as interpretações também de alguns setores de intelectuais não divergem muito da visão dos 
primeiros colonizadores. É interessante lembrar afirmações desses últimos dias, também de sociólogos famosos, em relação à votação maciça em favor de Lula pelo povo amazonense. Eis a explicação dada: "trata-se de uma população sem cultura, atrasada". É de se perguntar quem é o mais ignorante e quem o mais lúcido? Quem é selvagem é o capitalismo que invade, desmata, se apropria de terras, de minérios e da biodiversidade. Mata índios e posseiros, destrói as formas locais de vida. Lucra, não somente pelo trabalho, mas sobretudo pelo surplus, o excedente da ilegalidade de todos os jeitos de apropriação da riqueza, evasão fiscal, contrabando, corrupção dos cartórios e da justiça.

Na Amazônia existe um povo. Um povo que se mexe e com grandes tradições culturais e religiosas. À sua maneira, vai dizendo as coisas. Muitas vezes, fala pelo silêncio, pelo corpo encurvado como aquela viúva que foi falar com Jesus. Tão oprimida estava que o corpo estava todo encurvado. Mas, mesmo como o peso da opressão que encurva o corpo, o povo se manifesta. Não é de fazer muito barulho. Muitas vezes se organiza em cochichos para não serem impedidos de falar. Para ouvir os clamores desse povo é preciso silenciar e prestar mais atenção.

É preciso calar para ouvir a voz baixinha, quase um sussurro das mulheres que se articulam nas rodas de conversas, nos quintais, na porta das casas, nos becos das palafitas nas periferias de praticamente todas as cidades da Amazônia. A voz dos jovens que às vezes se apresenta nas danças, nas rodas de capoeira, nas frases improvisadas e criativas do hip hop. Nos pequenos grupinhos de jovens que se reúnem nas comunidades e até mesmo nas próprias casas para falar sobre "coisas de jovens" que nem sempre compreendemos. Na voz dos operários e das operárias que levantam de madrugada para chegar ao chão das fábricas, aos canteiros de obras, aos barcos de pesca, aos seringais e castanhais. É lá que está o povo. Não esperem o povo apenas nas missas, com suas igrejas cheias. É preciso ir ao encontro do povo.

Com muito acerto o Texto Base da CF 2007 demora em apresentar os diferentes povos da Amazônia e seus valores. Fala dos muitos povos indígenas que desenvolveram formas de convivência com a floresta e, recentemente, várias organizações em defesa de seus direitos. Fala dos quilombolas, comunidades de negros que resistiram à exploração dos brancos. Calcula-se que existam cerca de mil comunidades quilombolas, sobretudo no Maranhão e no Pará. São apresentados os migrantes do ciclo da borracha e a partir deles, com a liderança de Chico Mendes, o mártir floresta, surgiu e foi celebrada a Aliança dos Povos da Floresta, entre 
os Povos Indígenas e os Povos Extrativistas. São lembrados os ribeirinhos, que em vários lugares conseguiram preservar seus lagos, introduzindo uma legislação das águas considerada vanguarda no Brasil e respeitada em muitas partes do mundo.

Mais adiante, o texto fala dos posseiros e dos migrantes recentes que vieram e continuam vindo do Sul e do Sudeste, empurrados de um canto para outro do Brasil, mergulhado nos conflitos agrários. O governo joga o povo de um extremo ao outro do país par não resolver o problema da terra. É um problema muito antigo. Para resolver teria que fazer uma ampla reforma agrária que os governos nunca quiseram fazer. Os que tentaram, deixaram muito a desejar.

Por fim, o texto fala da população urbana das pequenas cidades localizadas às margens e beiradões dos grandes rios e dos igarapés. Também às margens das cidades, pequenas ou grandes. Nas periferias a população urbana sofre os efeitos de uma migração rápida e desordenada vinda diretamente das florestas ou das beiras para as cidades.

Por toda parte da Amazônia, encontramos um povo explorado. É verdade. Mas, como vimos, é um povo que se mexe. Um povo que vive e sobrevive. Cria novas formas de vida, novas solidariedades. A todo tempo se mobiliza para conquistar seus direitos. Se organiza nas formas tradicionais e inventam outras, segundo as novas necessidades.

\section{Para além da Campanha da Fraternidade}

A caminhada continua depois da CF 2007. A campanha ajudou muito. Principalmente ajudou a tornar a Amazônia mais conhecida e quem sabe mais respeitada. Mas, uma campanha, como o próprio nome diz, é apenas uma campanha. Logo termina e ninguém mais se lembra. Mas, o povo continua se mexendo, mesmo depois da campanha. Podemos lembrar as muitas organizações indígenas, as tradicionais e as novas em nível local, regional e pan-americano. Se organizam para fazer frente ao poder econômico e político que deseja o extermínio dos índios. Essa é uma luta de todos os países da grande Amazônia. Há mais de 500 anos eles lutam e resistem aos diversos tipos de colonizadores que vieram e continuam chegando até nos dias de hoje. Os índios lutam do seu jeito. Às vezes saem das suas comunidades, se pintam para guerra e acampam na Funai para exigir seus direitos. Outras vezes apenas rezam baixinho com seus pajés. Passam noites em vigília. Essa é sua forma de lutar. O Conselho Indigenista Missionário, o CIMI tem acompanhado todo esse processo e 
seus agentes são dignos de todos respeito. São homens e mulheres que deixam suas terras de origem e passam o resto da vida morando nas aldeias com os índios. Aprendem suas línguas, compartilham das suas crenças e comem com eles. Isso é profético.

As periferias das cidades da Amazônia estão repletas de índios. A presença deles nas cidades denuncia que alguma coisa não está indo bem nas suas comunidades. Principalmente para os jovens indígenas que caem na bebida para suportar o desemprego e a falta de oportunidades nas periferias das cidades. Muitos não vão à escola, caem nas drogas. O suicídio é outro problema entre os jovens indígenas nas cidades. Mas, eles também têm reagido. Criam alternativas. Ensinam a língua para as crianças. Exigem escolas nas numerosas comunidades indígenas nas cidades. Se preocupam com a educação, mesmo que ela seja uma imposição dos não-indígenas. Algumas etnias distintas têm se juntado para formar comunidades inter-étnicas. Isso é muito bonito. É a forma que eles têm encontrado para juntos enfrentar as dificuldades. Mesmo diante disso ainda tem gente que não consegue ver a luta dos povos indígenas. Por isso que é preciso olhar direito. Ver com outros olhos. Se deixar descolonizar para poder enxergar as maravilhas que o povo faz.

Em algumas regiões da Amazônia o Movimento dos Sem Terra, o MST, tem tido grande ênfase na organização dos pequenos camponeses. Em alguns lugares isso pode ter sido um erro porque os camponeses do Sul não conseguem produzir de acordo com a vocação da floresta. Eles estão acostumados a derrubar para plantar. Mas, tem muitos mudando a cabeça. Basta olhar para a Rede de Agricultores Tradicionais da Amazônia, a REATA. Ela reúne várias famílias de agricultores para fortalecer a sua organização e aprender com os povos indígenas e ribeirinhos como cultivar alimentos sem destruir a floresta. O MST tem aprendido muito com a Amazônia e tem levado esses ensinamentos para outras regiões do Brasil. É isso, a Amazônia também ensina e ainda tem muito a nos ensinar.

Muitas outras organizações camponesas têm aparecido na Amazônia. Muitas delas, animadas nas suas bases pelo pessoal da Comissão Pastoral da Terra, a CPT. Seus agentes têm enfrentado muita perseguição na região. Muito sangue tem sido derramado injustamente. Mas, é gente com coragem profética capaz de enfrentar até a morte. Uma delas todos conhecem. A Irmã Dorothy Stang. Uma missionária Americana assassinada em fevereiro de 2005, num assentamento no município de Anapu, no estado do Pará. Uma velhinha, da minha idade, covardemente assassinada porque se aliou à luta dos camponeses. Tem que ter coragem para ficar do lado do povo. 
Tem muitos grupos da Amazônia se organizando em nível nacional e até internacional. De modo especial os camponeses, os seringueiros, os povos indígenas, as mulheres. Lembramos alguns, mas, são muitos. Tem o Conselho Nacional de Comunidades Tradicionais, o Conselho Nacional dos Seringueiros, o Movimento Nacional dos Pescadores, a Coordenação Nacional dos Quilombolas, a Associação Internacional dos Ribeirinhos da Amazônia, o Movimento Nacional dos Sem Teto, o Movimento Nacional pela Educação, e assim por diante.

Em nível mais local, tem ainda inúmeras associações de mulheres que se juntam ao redor das castanheiras, piaçabeiras, tecedeiras de arumã, quebradeiras de coco de babaçu, pescadoras e as muitas iniciativas nos bairros de periferia das grandes cidades, sem esquecer as experiências da assim chamada "economia solidária" animada nas bases pela Cáritas e pela pastoral operária. Tem homens participando, mas, a maioria são mulheres que assumem a sua própria organização. Não esperam por ninguém. Vão abrindo caminhos. Do seu jeito e no seu tempo.

Muitos estudiosos estão atentos a estes movimentos que surgem nas bases e têm escrito muito sobre isso. Talvez o mais relevante nos últimos tempos tem sido o Projeto Nova Cartografia Social da Amazônia. Projeto vinculado às universidades locais que reúne muitos pesquisadores, professores, jovens estudantes com o objetivo de realizar a "autocartografia" dos povos e comunidades tradicionais na Amazônia. É um projeto que abrange todos os estados e até os países da região amazônica. Depois de acompanhar por um tempo as comunidades e grupos nas bases, os coordenadores elaboram um caderninho junto com o grupo. Nele, colocam suas histórias de vida, desenham o mapa da sua realidade, apontam os desafios e as expectativas dos grupos locais. Isso tem fortalecido e animado muito os movimentos sociais, tanto das cidades quanto do campo.

Desejo trazer aqui o parecer da professora Bertha Becker, livre-docente da Universidade Federal do Rio de Janeiro. Faz muitos anos que ela estuda a Amazônia e integrou a equipe de elaboração do Texto Base da Campanha da Fraternidade 2007. Cultiva grande admiração e respeito pela Amazônia e afirma que está crescendo o capital social da Amazônia, entendendo com isso a rede durável de relações humanas, mais ou menos institucionalizadas, de mútua familiaridade e reconhecimento. Ao observar o avanço da organização da sociedade civil, a descentralização política, a problemática ambientalista e os projetos alternativos de desenvolvimento, Becker afirmar que a Amazônia está se tornando 
uma "região em si", quer dizer, com estruturas produtivas e sociais próprias, com demandas particulares, e não uma simples fronteira para a expansão da economia e da população.

Essa afirmação é muito importante, pois permite quebrar aquela visão de uma região sempre dependente, sem autonomia própria, região atrasada, com grandes riquezas, mas incapaz de administrá-las. Segundo a professora Berta Becker, este capital social é recente, está em formação e tem origem na ação das Comunidades Eclesiais de Base, do Conselho Indigenista Missionário, da Comissão Pastoral da Terra e de outras pastorais, sem querer diminuir a importância de outras forças como os sindicatos, as associações, o Partido dos Trabalhadores. Isso só confirma nossa afirmação de que o povo tem se mexido e organizado. E a igreja tem aprendido muito com o povo.

\section{Conclusão}

Evidentemente, os desafios não faltam e são bem lembrados no texto da CF 2007. O caminho da libertação é sempre difícil, apresentando avanços e retrocesso, mas, é um caminho já traçado. É o povo que acha dentro da vida o caminho que leva à libertação, como afirma o poeta. Quem deseja ajudar a Amazônia, em primeiro lugar, deve reconhecer tudo isso.

Esse crescimento do capital social da Amazônia foi e está sendo possível pela capacidade de seu povo, por sua sabedoria, sua paciência, sua capacidade de luta, sua criatividade. Isso deve ser conhecido e valorizado, em primeiro lugar pelos próprios habitantes da Amazônia por séculos considerados como incapazes e deixados em segundo lugar. Pelos outros que pretendem colaborar neste caminho de libertação. Será possível na medida em que se deixar uma atitude colonialista, ainda existente, para uma atitude de verdadeiro diálogo.

A Igreja desde o tempo da colonização está presente nessa região, participando desses desafios e dessas contradições. Como vimos, sobretudo a partir do documento de Santarém, 1972, onde opta pelo caminho da encarnação e da libertação, e do documento de Manaus, "A Igreja se faz carne e arma sua tenda na Amazônia", 1997, no qual apresenta um rosto mais pobre e amazônico. Estes documentos contribuíram e ainda estão contribuindo para uma caminhada de libertação. Não podemos negar suas fraquezas, suas necessidades de novos instrumentos materiais e humanos, suas contradições, mas, é uma Igreja já adulta, 
criativa e com experiências que podem ajudar e ser de modelo para outras igrejas em outras regiões do Brasil e do mundo.

A Igreja amazônica valoriza o aspecto sacramental da liturgia da palavra e do serviço concreto aos irmãos mais necessitados. É uma Igreja mais leiga, seja porque dinamizada em milhares de comunidades por leigos e leigas, seja porque preocupada em se abrir à problemática social com as muitas pastorais sociais.

É uma Igreja preocupada com a problemática da inculturação, procurando dialogar mais com as outras religiões, sobretudo com a espiritualidade indígena.

O caminho a ser percorrido é muito grande, mas não faltam experiências promissoras que podem servir de exemplo também para outros lugares. É uma Igreja que pisa no chão e na lama da Amazônia. Uma Igreja que quer conhecer a Amazônia e precisa ir ao encontro das pessoas para caminhar junto com o povo. Para isso, é preciso visitar e ficar tempo com eles nas suas comunidades, nas aldeias e nas periferias das cidades. Não é somente passar uma vez e ir embora. É preciso retornar sempre e andar por aí no meio do povo. Ouvir mais e falar menos. Contemplar o povo, acolher seus clamores, rezar junto, somar-se com eles e, acima de tudo, deixar-se ensinar pela sua sabedoria.

Por todas essas razões, o documento da CF 2007, na parte do "julgar", afirma que é verdade que a Amazônia precisa de todos nós. Mas, é também verdade que todos nós precisamos da Amazônia. Não somente por sua importância para a sobrevivência do planeta, mas, sobretudo porque seus povos podem nos ensinar os segredos da vida para as futuras gerações.

Falei no início da necessidade de uma profunda conversão nossa. A Amazônia exige de nós um diálogo constante com as outras culturas; um diferente conceito de território e ambiente; um diferente conceito de natureza; um diferente conceito de relações; um diferente conceito de propriedade; um diferente conceito de produção.

E, por fim, retomo novamente o poeta que diz: "o que em nós hoje é palavra, no povo vai ser ação". Eis então os desafios!

\section{Referências}

BECKER, Berta K. Organização e conflitos na sociedade civil da Amazônia. In: TADA, Cecília; MATA, Raimundo Possidônio C. (Org.) Amazônia - Desafios e Perspectivas para a Missão. São Paulo: Paulinas, 2005, p.83-108. 
MELLO, Thiago de. Faz escuro, mas eu canto. Rio de Janeiro: Civilização Brasileira, 1965.

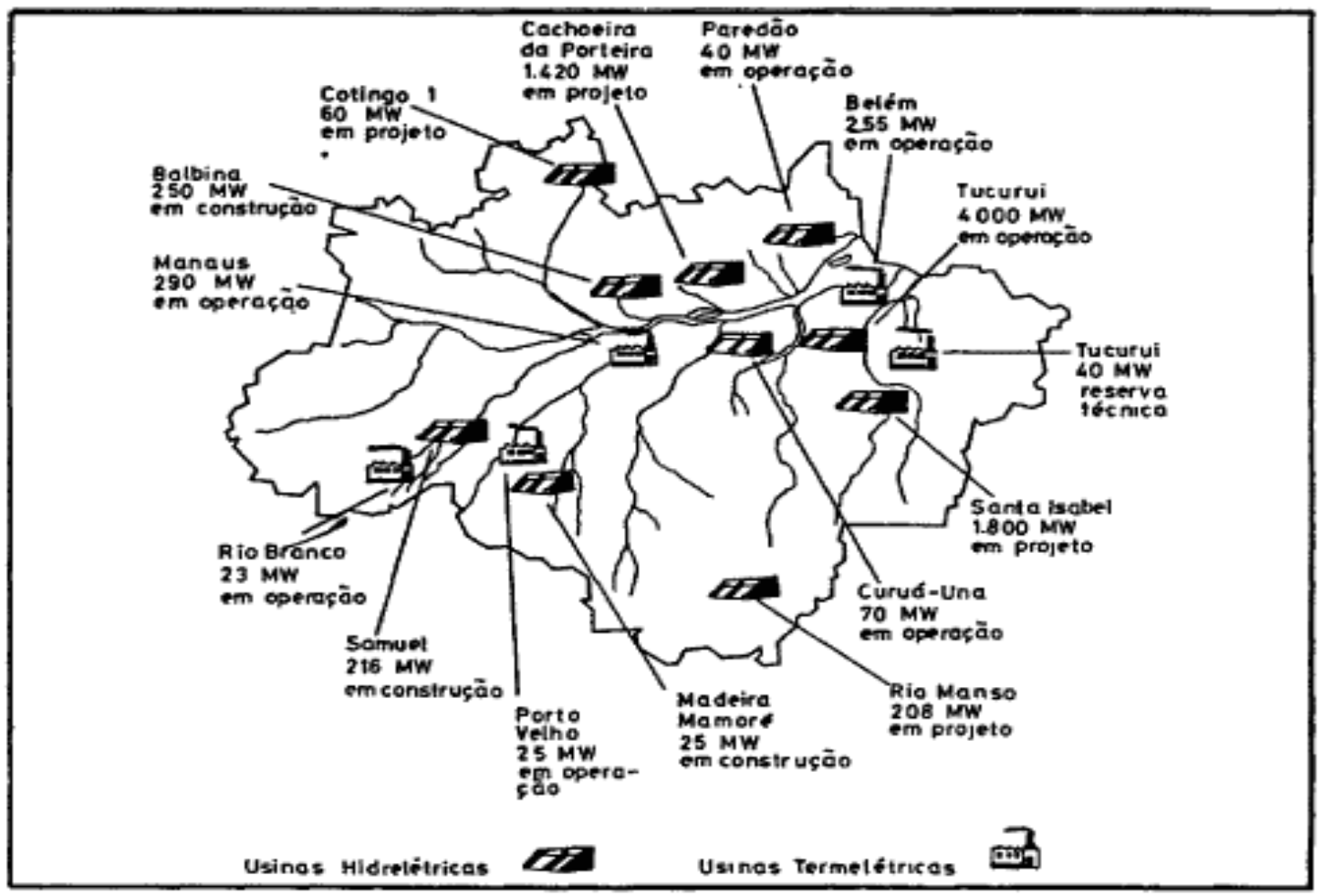

Figura I: Situafato atual da produgato da energia eletrica nas bacias dos rios Amazonas e Tocantins/Araguaia (Fonte: Eletronorte)

\section{Dados do autor}

Cláudio Perani

Homenageado desta Edição Especial. 